Check for updates

Cite this: Chem. Commun., 2019, 55,12304

Received 28th July 2019,

Accepted 18th September 2019

DOI: $10.1039 /$ c9cc05495b

rsc.li/chemcomm

\section{Direct bromocarboxylation of arynes using allyl bromides and carbon dioxide $\dagger$}

\author{
Yu Zhang, Wenfang Xiong, Jinghe Cen, Wuxin Yan, Yaodan Wu, Chaorong Qi, D \\ Wanqing Wu (D) and Huanfeng Jiang (D)*
}

An unprecedented three-component coupling involving arynes, allyl bromides, and $\mathrm{CO}_{2}$ is described, providing efficient and facile access to structurally diverse ortho-brominated aryl esters. Unlike the conventional role played in organic synthesis as electrophiles, organic bromides served as nucleophiles in this reaction, affording a new approach to multicomponent reactions (MCRs) involving aryne intermediates. Additionally, Hammett analysis suggests that two reaction mechanisms exist, depending on the electronic nature of the cinnamyl bromides used.

Arynes have become versatile synthetic tools in organic synthesis, especially for the construction of diverse 1,2-functionalized aromatic rings. ${ }^{1}$ Due to their highly electrophilic strained triple bond, arynes can undergo different types of reactions such as cycloaddition reaction, multicomponent coupling, and insertion reaction to realize the double functionalization. Among them, the combination of organic halides and arynes with various nucleophiles provides an alternative way to preserve halogen atoms or organic parts in the final products. Typically, organic halides such as $\alpha$-bromo ketones ${ }^{2}$ can undergo nucleophilic attack by in situ zwitterions or nucleophiles to afford the corresponding alkylated products (Scheme 1, Mode 1). On the other hand, the incorporation of halogen atoms into arynes, which greatly influences the pharmacological activities of bioactive molecules ${ }^{3}$ and is utilized for diverse functional group transformations, ${ }^{4}$ can be accomplished by using alkynyl or polyfluoroaryl bromides, ${ }^{5 a, g}$ perfluoroalkyl $^{5 b, c}$ or alkynyl iodides, ${ }^{5 d, e}$ and carbon tetrachloride ${ }^{5 f, g}$ (Scheme 1, Mode 2).

Despite these elegant studies described, as far as we know, there has been no precedent utilizing organic halides as nucleophiles to trigger MCRs involving aryne intermediates. Inspired by Yoshida's brilliant work ${ }^{6}$ that arynes could be inserted into the

Key Lab of Functional Molecular Engineering of Guangdong Province, School of Chemistry and Chemical Engineering, South China University of Technology, Guangzhou 510640, P. R. China. E-mail: jianghf@scut.edu.cn $\dagger$ Electronic supplementary information (ESI) available: Experimental details and characterization of all compounds, and copies of ${ }^{1} \mathrm{H}$ and ${ }^{13} \mathrm{C}$ NMR spectra for selected compounds. See DOI: 10.1039/c9cc05495b
$\mathrm{C}-\mathrm{X} \sigma$-bonds of acid halides and the fact that arynes could even be initiated with different solvents such as THF, ${ }^{5 a, 7} \mathrm{DMF}^{8}$ and DMSO, ${ }^{9}$ we envisaged that the benzyne intermediate generated in situ might undergo nucleophilic attack by the halogen atoms of organic halides, and the corresponding zwitterions might capture another electrophilic reagent to furnish the functionalized halobenzenes. ${ }^{10}$ Additionally, given that $\mathrm{CO}_{2}$ is an inexpensive, safe and renewable $\mathrm{C} 1$ building block, the transformation of $\mathrm{CO}_{2}$ into high value-added products shows great potential in organic synthesis and has attracted numerous organic chemists' attention. ${ }^{11}$ However, very limited success involving both $\mathrm{CO}_{2}$ and arynes has been achieved so far. ${ }^{12}$

Recently, we ${ }^{12 g}$ reported a 3P-4CR of arynes to afford diverse $o$-chlorobenzoates using $\mathrm{KCl}$ as a $\mathrm{Cl}$ source. Surprisingly, we found that the reaction could give a moderate yield of allyl 2-bromobenzoate 3aa when the solvent DCE (1,2-dichloroethane) was replaced with allyl bromide even without $\mathrm{KBr}$. Therefore, as part of our continuous interest in the utilization of $\mathrm{CO}_{2}{ }^{13}$ herein, we report an unprecedented three-component coupling reaction of arynes, allyl bromides and $\mathrm{CO}_{2}$. Compared with our previous studies, the reaction proceeded well without any additional

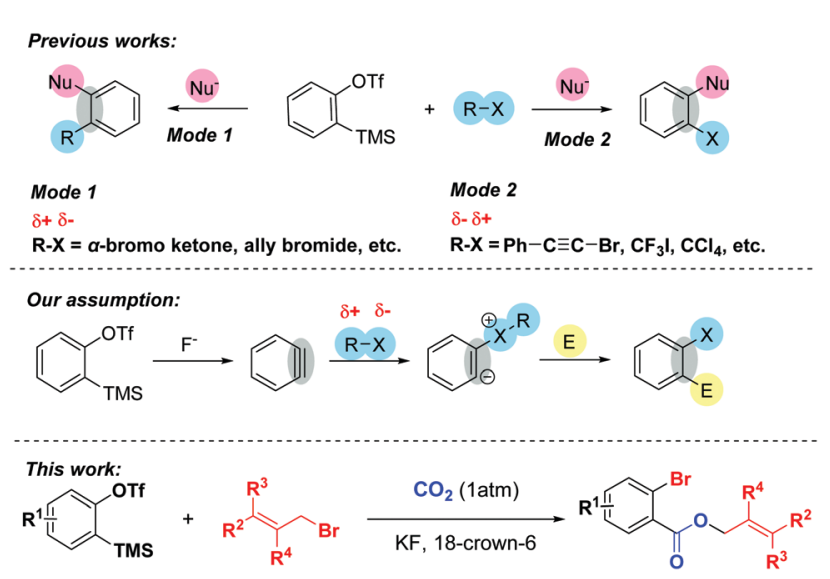

Scheme 1 Background and our approach. 

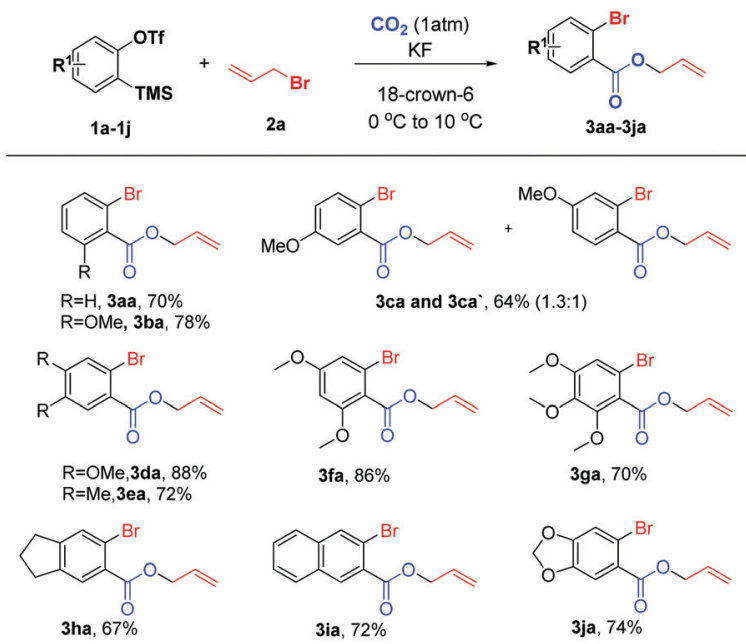

3ga, $70 \%$

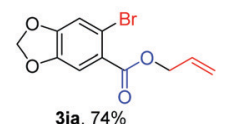

Scheme 2 Reaction conditions: 1 a $(0.2 \mathrm{mmol}), 2 \mathrm{a}(0.5 \mathrm{~mL}), \mathrm{CO}_{2}(1 \mathrm{~atm})$, KF (4 equiv.), 18 -crown-6 (4 equiv.), 0 to $10{ }^{\circ} \mathrm{C}$ for $12 \mathrm{~h}$.

inorganic salts and the incorporation of both $\mathrm{Br}$ and $\mathrm{CO}_{2}$ into the arynes made further facile functionalizations possible.

We initially investigated the reaction of aryne precursor $\mathbf{1 a}^{\mathbf{1 4}}$ with allyl bromide 2a under $1 \mathrm{~atm} \mathrm{CO}_{2}$ at $46{ }^{\circ} \mathrm{C}$ for $12 \mathrm{~h}$, and observed that the three-component coupling product 3aa was obtained in $52 \%$ yield. After screening of temperatures, we were delighted to discover that the reaction yield could be optimized to $79 \% .{ }^{15}$ The reaction system could be compatible with various benzyne precursors (Scheme 2), especially for those containing the methoxy group, affording allyl $o$-bromobenzoate derivatives in good to excellent yields. As expected, the reaction of 4-methoxybenzyne (generated from 1c) provided the corresponding product in $64 \%$ yield with poor regioselectivity (1.3:1). Moreover, both multisubstituted symmetrical and unsymmetrical silyl aryl triflates $(\mathbf{1 d - 1 g})$ reacted smoothly with complete regioselectivity ${ }^{16}$ under the reaction conditions. Furthermore, indanyl and 1,3-benzodioxole derivatives (1/h and $\mathbf{1 j}$ ) as well as 2,3-naphthalyne (1i) could also work well, furnishing the expected products in $67-74 \%$ yields. However, the reaction of the 4,5-difluoroaryne precursor with allyl bromide 2 a resulted in a much lower yield.

Encouraged by these preliminary results, we then directed our attention to the optimization of non-terminal allyl bromide 2b (Table 1). Among the different solvents examined, $\mathrm{CF}_{3}-\mathrm{Ph}$ was found to be the best solvent, whereas the other solvents afforded inferior results (entries 1-4). The reaction yield could be further improved to $56 \%$ by performing the reaction at $-10{ }^{\circ} \mathrm{C}$ and gradually warming the reaction mixture to $10{ }^{\circ} \mathrm{C}$ (entry 5). Remarkably, when we proportionally decreased the dosages of both the aryne precursor and F source, the yield of 3ab increased to $66 \%$ (entries 5-7). To our delight, a similar result was achieved even when the amounts of KF and 18-crown-6 were reduced to 2.4 equivalents (entry 8). Finally, diluting the reaction mixture and altering the charging way of $\mathbf{2 b}$ gave the best result, with $3 \mathrm{ab}$ obtained in $76 \%$ yield (entry 10 ). The control experiments indicated that both 18-crown- 6 and $\mathrm{CO}_{2}$ were essential for transformation (entries 11 and 12).
Table 1 Optimization of reaction conditions ${ }^{a}$

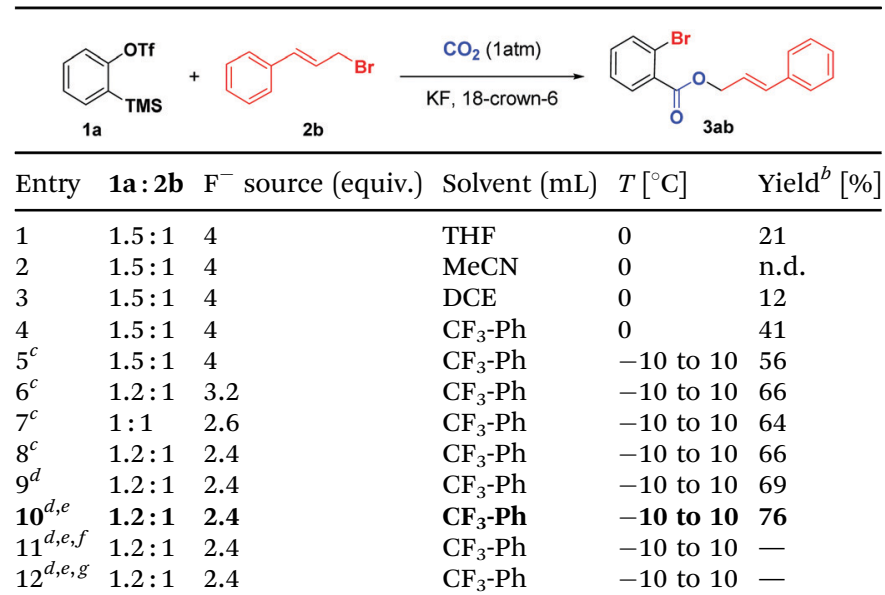

${ }^{a}$ Reaction conditions: $2 \mathbf{b}$ ( $\left.0.2 \mathrm{mmol}\right), \mathrm{KF}$ (4 equiv.) and 18-crown-6 (4 equiv.) in solvent $(0.1 \mathrm{~mL}), \mathrm{CO}_{2}(1 \mathrm{~atm}), 12 \mathrm{~h} .{ }^{b}$ Determined by ${ }^{1} \mathrm{H}$ NMR analysis using $\mathrm{CH}_{3} \mathrm{NO}_{2}$ as an internal standard. ${ }^{c} \mathrm{CF}_{3}-\mathrm{Ph}(0.5 \mathrm{~mL})$. ${ }^{d} \mathrm{CF}_{3}-\mathrm{Ph}(1.0 \mathrm{~mL}) .{ }^{e} 2 \mathbf{b}$ was added in the $\mathrm{N}_{2}$ glove box ${ }^{f}$ Without 18-crown-6. ${ }^{g}$ Under a $\mathrm{N}_{2}$ atmosphere.

Next, we examined various cinnamyl bromides ${ }^{17}$ under the optimized reaction conditions, and the results are shown in Scheme 3. To our delight, a broad range of cinnamyl bromides (3ab-3ai) reacted smoothly to afford the corresponding carboxylated products in moderate to good yields, allowing $\mathrm{F}, \mathrm{Cl}$, $\mathrm{Br}, \mathrm{NO}_{2}$, and $\mathrm{CF}_{3}$ substituents on the aryl ring to be tolerated. Intriguingly, cinnamyl bromides with electron-neutral groups provided higher yields than those with electron-withdrawing or electron-donating groups, and the substrates with electrondonating groups (3af and 3ag) led to dramatic decreases in the yields of the products. In addition, both disubstituted and 1-naphthyl-substituted cinnamyl bromides (3aj-3al) were suitable reaction partners, leading to the desired products in $64-71 \%$ yields. Furthermore, the substrate scope was further expanded to the allyl groups at different positions with various substituents

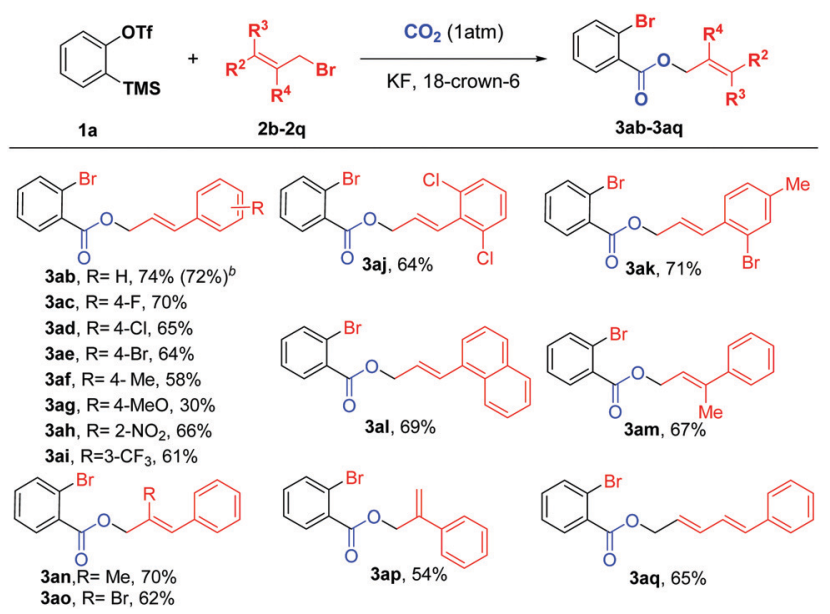

Scheme $3{ }^{a}$ Reaction conditions: 1a $(0.24 \mathrm{mmol}), 2(0.2 \mathrm{mmol}), \mathrm{CO}_{2}$ (1 atm), KF (2.4 equiv.), 18-crown-6 (2.4 equiv.), $\mathrm{CF}_{3}-\mathrm{Ph}(1 \mathrm{~mL}),-10$ to $10{ }^{\circ} \mathrm{C}$ for $12 \mathrm{~h}$. ${ }^{b}$ Reaction conditions: $1 \mathrm{a}(1.2 \mathrm{mmol}), 2$ ( $\left.1 \mathrm{mmol}\right), \mathrm{CO}_{2}$ (balloon), KF (2.4 equiv.), 18 -crown-6 (2.4 equiv.), $\mathrm{CF}_{3}-\mathrm{Ph}(5 \mathrm{~mL}),-10$ to $10{ }^{\circ} \mathrm{C}$ for $12 \mathrm{~h}$. 


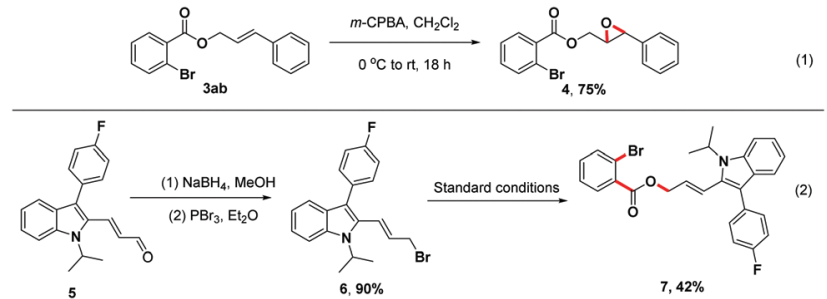

Scheme 4 Synthetic applications.

(3am-3ap), all of which were compatible with our reaction system. Moreover, when 1-bromo-5-phenyl-2,4-pentadiene (2q) was employed, 3aq could also be obtained in $65 \%$ yield, thus demonstrating the versatility of this new protocol.

To further illustrate the utility of this unique three-component reaction, treatment of product $3 \mathbf{a b}$ with $m$-chloroperoxybenzoic acid ( $m$-CPBA) in $\mathrm{CH}_{2} \mathrm{Cl}_{2}$ provided the desired epoxide derivative $\mathbf{4}$ in $75 \%$ isolated yield ${ }^{18 a}$ (Scheme 4, (1)). Moreover, the indole derivative 5, a synthetic precursor for the construction of Fluvastatin, ${ }^{18 b, c}$ underwent reduction and bromination efficiently to afford brominated compound $\mathbf{6}$, which could be transformed to the structurally complex product 7 in $42 \%$ isolated yield using this one-step strategy (Scheme 4, (2)).

To shed light on the mechanism of this difunctionalization reaction of arynes, a series of control experiments were performed (Scheme 5). Compared with cinnamyl bromide $2 \mathbf{b}$, the reaction of cinnamyl chloride $2 \mathbf{r}$ with aryne precursor $\mathbf{1 a}$ failed to give the target product 3ar, while cinnamyl iodine $2 \mathrm{~s}$ could only afford the corresponding product 3as in $23 \%$ yield (based on ${ }^{1} \mathrm{H}$ NMR), with iodobenzene and ortho-diiodobenzene as the main side products (detected by GC-MS). These observations indicated that cinnamyl bromide possessed a more appropriate nucleophilicity
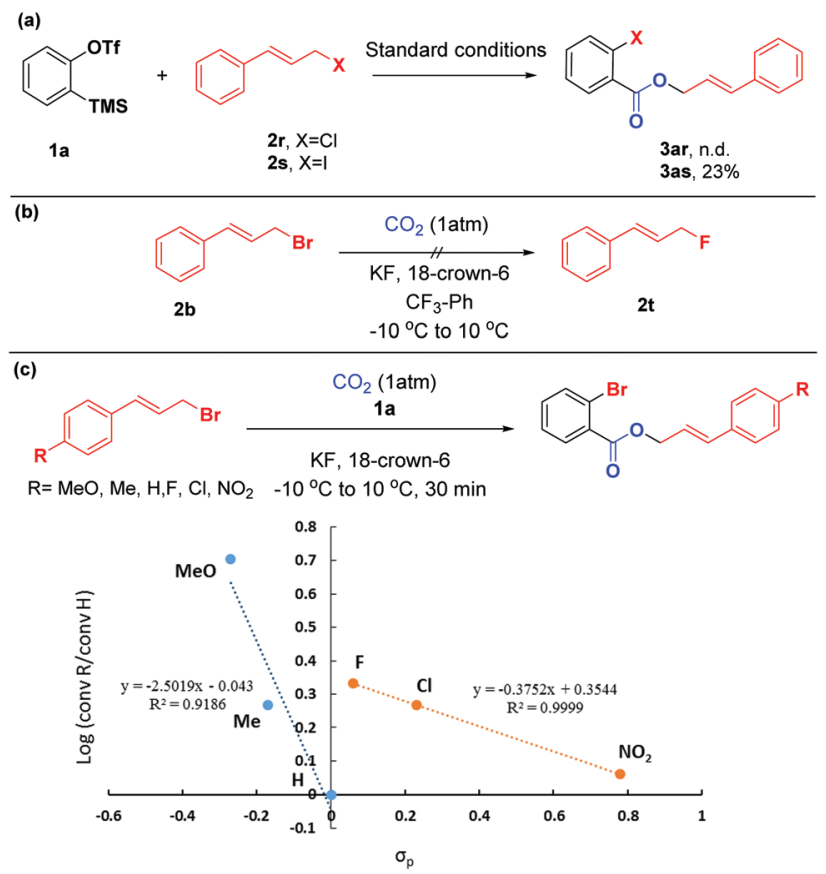

Scheme 5 Mechanistic experiments.

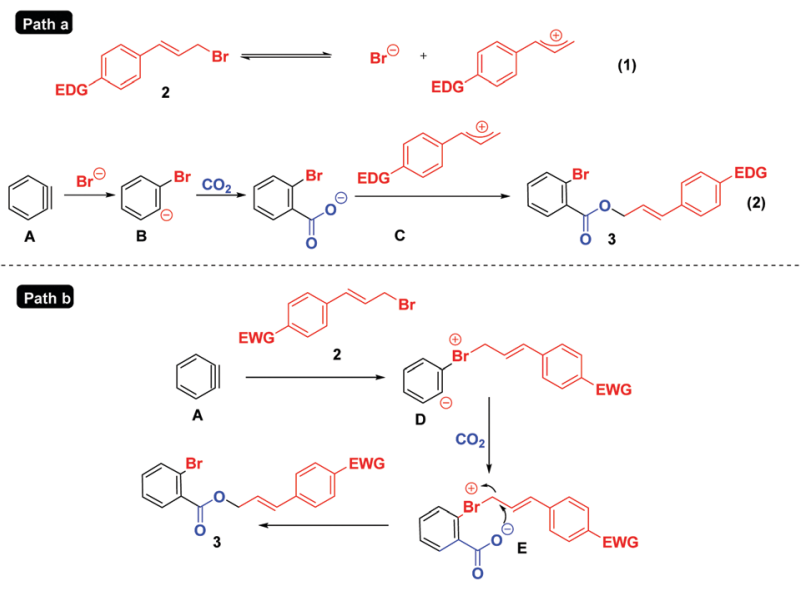

Scheme 6 Plausible mechanisms.

toward arynes. Additionally, given that the organic bromide might undergo nucleophilic fluorination by $\mathrm{KF}^{19}$ we conducted the reaction without aryne precursor 1a. To our surprise, the formation of $2 \mathbf{t}$ was not detected by ${ }^{19} \mathrm{~F}$ NMR spectroscopy (Scheme 5(b)). We further evaluated the electronic effects of this reaction by Hammett analysis. ${ }^{20}$ The two lines with different negative $\rho$ values indicated that a considerable build-up of positive charge in the transition state, however, with a change in the mechanism or rate-determining step, depending on the character of the substituents on the cinnamyl bromides. For substituents with $\sigma_{\mathrm{p}}<0$, the value $\rho=-2.5$ was consistent with an $\mathrm{S}_{\mathrm{N}} 1$-like mechanism. ${ }^{21}$ But in the case of electron deficient substrates, the sensitivity constant $\rho$ was only -0.4 , which might proceed in a different way (Scheme 5(c)).

Based on the above results and previous studies, ${ }^{6,12}$ two tentative mechanisms are proposed in Scheme 6. For substrates containing electron-rich/-neutral groups (Path a), the ionization ${ }^{22}$ of 2 generates a cinnamyl cation and $\mathrm{Br}^{-}$; the latter reacts with aryne intermediate $\mathbf{A}, \mathrm{CO}_{2}$ and the cinnamyl cation successively to deliver the final products 3. However, in the case of electron deficient substrates (Path b), which do not easily undergo the ionization process due to the instability of the cinnamyl cation, the reaction may proceed as follows: the nucleophilic attack of cinnamyl bromide $\mathbf{2}$ on the benzyne intermediate $\mathbf{A}$ affords the 1,3-zwitterion $\mathbf{D}$, which is then intercepted by $\mathrm{CO}_{2}$ to form the 1,5-zwitterion E. Finally, a subsequent intramolecular nucleophilic attack of intermediate $\mathbf{E}$ yields cinnamyl 2-bromobenzoates 3.

In summary, we have developed an efficient three-component reaction of $\mathrm{CO}_{2}$ with arynes and allyl bromides to construct various allyl $o$-bromobenzoate scaffolds. The reaction demonstrates the first example using cinnamyl bromide as a nucleophile in MCRs of arynes and helps deepen our understanding of the high electrophilicity of the aryne intermediate. Further studies focusing on the transformation of $\mathrm{CO}_{2}$ are ongoing in our laboratory.

We thank the National Program on the Key Research Project (2016YFA0602900), the National Natural Science Foundation of China (21420102003) and the Guangdong Natural Science Foundation (2018B030308007) for financial support. 


\section{Conflicts of interest}

There are no conflicts to declare.

\section{Notes and references}

1 For reviews on arynes, see: (a) R. Sanz, Org. Prep. Proced. Int., 2008, 40, 215; (b) H. Yoshida, J. Ohshita and A. Kunai, Bull. Chem. Soc. Jpn., 2010, 83, 199; (c) P. M. Tadross and B. M. Stoltz, Chem. Rev., 2012, 112, 3550; (d) A. Bhunia, S. R. Yetra and A. T. Biju, Chem. Soc. Rev., 2012, 41, 3140; (e) K. Okuma, Heterocycles, 2012, 85, 515; $(f)$ A. V. Dubrovskiy, N. A. Markina and R. C. Larock, Org. Biomol. Chem., 2013, 11, 191; $(g)$ S. S. Bhojgude, A. Bhunia and A. T. Biju, Acc. Chem. Res., 2016, 49, 1658; (h) J. A. García-López and M. F. Greaney, Chem. Soc. Rev., 2016, 45, 6766; (i) T. Roya and A. T. Biju, Chem. Commun., 2018, 54, 2580; $(j)$ H. Takikawa, A. Nishii, T. Sa-kaib and K. Suzuki, Chem. Soc. Rev., 2018, 47, 8030.

2 (a) W.-M. Shu, J.-R. Ma, K.-L. Zheng and A.-X. Wu, Org. Lett., 2016, 18, 196; (b) Y. Li, D. Qiu, R. Gu, J. Wang, J. Shi and Y. Li, J. Am. Chem. Soc., 2016, 138, 10814. Also see ref. 14g.

3 M. Z. Hernandes, S. M. T. Cavalcanti, D. R. Moreira, W. F. A. Junior and A. C. L. Leite, Curr. Drug Targets, 2010, 11, 303.

4 (a) R. Martin and S. L. Buchwald, Acc. Chem. Res., 2008, 41, 1461; (b) J. F. Hartwig, Acc. Chem. Res., 2008, 41, 1534; (c) J. Ruan and J. Xiao, Acc. Chem. Res., 2011, 44, 614; (d) O. Baudoin, Acc. Chem. Res., 2017, 50, 1114.

5 (a) H. Yoshida, Y. Asatsu, Y. Mimura, Y. Ito, J. Ohshita and K. Takaki, Angew. Chem., 2011, 123, 9850; (b) Y. Zeng and J. Hu, Chem. - Eur. J., 2014, 20, 6866; (c) Y. Zeng, G. Li and J. Hu, Angew. Chem., Int. Ed., 2015, 54, 10773; (d) Y. Zeng, L. Zhang, Y. Zhao, C. Ni, J. Zhao and J. Hu, J. Am. Chem. Soc., 2013, 135, 2955; (e) Y. Zeng and J. Hu, Org. Lett., 2016, 18, 856; $(f)$ S.-J. Li, Y. Wang, J.-K. Xu, D. Xie, S.-K. Tian and Z.-X. Yu, Org. Lett., 2018, 20, 4545; (g) M. Zhou, C. Ni, Y. Zeng and J. Hu, J. Am. Chem. Soc., 2018, 140, 6801.

6 H. Yoshida, Y. Mimura, J. Ohshita and A. Kunai, Chem. Commun., 2007, 2405.

7 (a) K. Okuma, Y. Fukuzaki, A. Nojima, A. Sou, H. Hino, N. Matsunaga, N. Nagahora, K. Shioji and Y. Yokomori, Bull. Chem. Soc. Jpn., 2010, 83, 1238; (b) M. Thangaraj, S. S. Bhojgude, M. V. Maneb and A. T. Biju, Chem. Commun., 2016, 52, 1665.

8 For selected reports, see: (a) E. Yoshioka, S. Kohtani and H. Miyabe, Org. Lett., 2010, 12, 1956; (b) H. Yoshida, Y. Ito and J. Ohshita, Chem. Commun., 2011, 47, 8512; (c) E. Yoshioka, S. Kohtani and H. Miyabe, Angew. Chem., Int. Ed., 2011, 50, 6638; (d) E. Yoshioka, H. Tanaka, S. Kohtani and H. Miyabe, Org. Lett., 2013, 15, 3938; (e) F. Liu, H. Yang, X. Hu and G. Jiang, Org. Lett., 2014, 16, 6408.

9 (a) F.-L. Liu, J.-R. Chen, Y.-Q. Zou, Q. Wei and W.-J. Xiao, Org. Lett., 2014, 16, 3768; (b) H.-Y. Li, L.-J. Xing, M.-M. Lou, H. Wang, R.-H. Liu and B. Wang, Org. Lett., 2015, 17, 1098; (c) H. Hazarika, K. Neog, A. Sharma, B. Das and P. Gogoi, J. Org. Chem., 2019, 84, 5846.

10 Other methods for the incorporation of halogen atoms into arynes. (a) D. Rodríguez-Lojo, A. Cobas, D. Peña, D. Pérez and E. Guitián,
Org. Lett., 2012, 14, 1363; (b) H. Yoshida, R. Yoshida and K. Takaki, Angew. Chem., Int. Ed., 2013, 52, 8629; (c) C. E. Hendrick, S. L. McDonald and Q. Wang, Org. Lett., 2013, 15, 3444; (d) C. E. Hendrick and Q. Wang, J. Org. Chem., 2015, 80, 1059; (e) S. Bhattacharjee, A. Guin, R. N. Gaykar and A. T. Biju, Org. Lett., 2019, 21, 4383; also see ref. 6 and $14 g$.

11 For recent reviews on $\mathrm{CO}_{2}$ chemistry, see: (a) L. Zhang and Z. Hou, Chem. Sci., 2013, 4, 3395; (b) Q. Liu, L. Wu, R. Jackstell and M. Beller, Nat. Commun., 2015, 6, 5933; (c) K. Sekine and T. Yamada, Chem. Soc. Rev., 2016, 45, 4524; (d) A. Tortajada, F. Juliá-Hernández, M. Börjesson, T. Moragas and R. Martin, Angew. Chem., Int. Ed., 2018, 57, 15948; (e) S. Wang and C. Xi, Chem. Soc. Rev., 2019, 48, 382; (f) C. S. Yeung, Angew. Chem., Int. Ed., 2019, 58, 5492.

12 (a) H. Yoshida, H. Fukushima, J. Ohshita and A. Kunai, J. Am. Chem. Soc., 2006, 128, 11040; (b) H. Yoshida, T. Morishita and J. Ohshita, Org. Lett., 2008, 10, 3845; (c) W. J. Yoo, T. V. Q. Nguyen and S. Kobayashi, Angew. Chem., Int. Ed., 2014, 53, 10213; (d) T. Kaicharla, M. Thangaraj and A. T. Biju, Org. Lett., 2014, 16, 1728; (e) S. S. Bhojgude, T. Roy, R. G. Gonnade and A. T. Biju, Org. Lett., 2016, 18, 5424; $(f)$ W. Xiong, C. Qi, R. Cheng, H. Zhang, L. Wang, D. Yan and H. Jiang, Chem. Commun., 2018, 54, 5835; (g) H. Jiang, Y. Zhang, W. Xiong, J. Cen, L. Wang, R. Cheng, C. Qi and W. Wu, Org. Lett., 2019, 21, 345.

13 (a) W. Xiong, C. Qi, H. He, L. Ouyang, M. Zhang and H. Jiang, Angew. Chem., Int. Ed., 2015, 54, 3084; (b) W. Xiong, C. Qi, Y. Peng, T. Guo, M. Zhang and H. Jiang, Chem. - Eur. J., 2015, 21, 14314; (c) Y. Peng, J. Liu, C. Qi, G. Yuan, J. Li and H. Jiang, Chem. Commun., 2017, 53, 2665; (d) W. Xiong, C. Qi, T. Guo, M. Zhang, K. Chen and H. Jiang, Green Chem., 2017, 19, 1642; (e) W. Xiong, D. Yan, C. Qi and H. Jiang, Org. Lett., 2018, 20, 672; $(f)$ H. Jiang, H. Zhang, W. Xiong, C. Qi, W. Wu, L. Wang and R. Cheng, Org. Lett., 2019, 21, 1125.

14 Y. Himeshima, T. Sonoda and H. Kobayashi, Chem. Lett., 1983, 1211. 15 See the ESI $\dagger$ for details.

16 (a) J. M. Medina, J. L. Mackey, N. K. Garg and K. N. Houk, J. Am. Chem. Soc., 2014, 136, 15798; (b) E. Picazo, K. N. Houk and N. K. Garg, Tetrahedron Lett., 2015, 56, 3511.

17 Other organic bromides were also investigated. When (3-bromoprop-1yn-1-yl)benzene, (bromomethyl)benzene or ethyl 2-bromoacetate was used instead of cinnamyl bromides, the reactions could provide the corresponding products in $44 \%, 52 \%$ and $42 \%$ yields, respectively.

18 (a) Q. Yao, H. Yu, H. Zhang, S. Dong, F. Chang, L. Lin, X. Liu and X. Feng, Chem. Commun., 2018, 54, 3375; (b) J. T. Zacharia, T. Tanaka and M. Hayashi, J. Org. Chem., 2010, 75, 7514; (c) V. K. A. Kalalbandi, J. Seetharamappa and U. Katrahalli, RSC Adv., 2015, 5, 38748.

19 (a) E. Lee and D. V. Yandulov, J. Fluorine Chem., 2009, 130, 474; (b) K. Dempsey, R. Mir, I. Smajlagic and T. Dudding, Tetrahedron, 2018, 74, 3507.

20 C. Hansch, A. Leo and R. W. Taft, Chem. Rev., 1991, 91, 165.

21 (a) K. A. Mix and R. T. Raines, Org. Lett., 2015, 17, 2358; (b) E. V. Anslyn and D. A. Dougherty, Modern Physical Organic Chemistry, University Science Books, Sausalito, CA, 2006.

22 B. Denegri, A. R. Ofial, S. Jurić, A. Streiter, O. Kronja and H. Mayr, Chem. - Eur. J., 2006, 12, 1657. 